\title{
Growing ecologies: Growing communities
}

\author{
Review by Matthew Potteiger, College of Environmental \\ Science and Forestry, State University of New York*
}

Review of The Community Food Forest Handbook: How to Plan, Organize, and Nurture Edible Gathering Places, by Catherine Bukowski and John Munsell. (2018). Chelsea Green Publishing. Available in paperback and Kindle; 272 pages. Publisher's website: https://www.chelseagreen.com/product/thecommunity-food-forest-handbook/

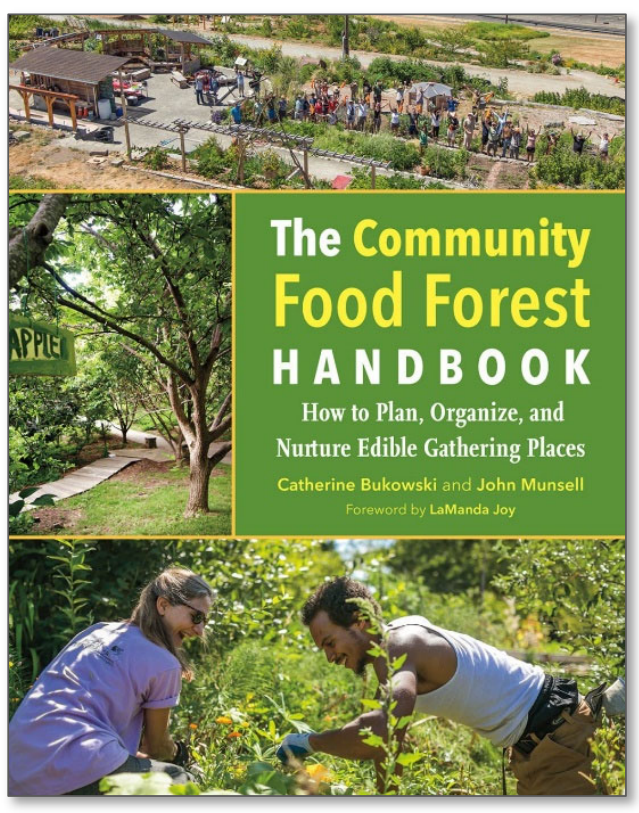

Submitted November 22, 2019 / Published online March 6, 2020

Citation: Potteiger, M. (2020). Growing ecologies: Growing communities [Book review]. Journal of Agriculture, Food Systems, and Community Development, 9(2), 283-285. https://doi.org/10.5304/jafscd.2020.092.022

Copyright (C) 2020 by the Author. Published by the Lyson Center for Civic Agriculture and Food Systems. Open access under CC-BY license.

$\mathrm{T}$ he contemporary community gardening and urban agriculture movements have transformed the fundamental notion of the city, chal-

* Matthew Potteiger is a professor of landscape architecture at SUNY-ESF, where the focus of his teaching, research, and public service is on the design of food and landscape systems. His interdisciplinary food system studio has worked with diverse communities on projects for urban agriculture, markets, and other public spaces in the food system. He is a cofounder of Syracuse Grows, a resource networking and advocacy organization, and the Salt City Harvest Farm, a 50acre (20-hectare) community farm in collaboration with New American refugees. Following an interest in foraging has led him to explore the design of large-scale productive ecologies. He can be reached at the Department of Landscape Architecture, College of Environmental Science and Forestry, State University of New York; 1 Forestry Drive; Syracuse, NY 13210 USA; mpotteig@syr.edu lenging the urban/rural dichotomy and applying an agronomic model to remake urban spaces as productive systems. Recently, another model has emerged, that of the food forest, which is based on the form and function of forest ecosystems for producing food. Much like the early innovative efforts of urban agriculture, community supported agriculture operations (CSAs), and other alternative food system projects, the emergence of food forests across the country has been a grassroots effort informed by a few key references and with little coordination across individual efforts.

The Community Food Forest Handbook: How to Plan, Organize, and Nurture Edible Gathering Places provides a very timely and thorough overview of this new type of productive landscape. Of the 30 food forest projects that form the basis of the 
book, only one has been in existence for more than 10 years. The authors, Catherine Bukowski, a Ph.D. candidate at Virginia Tech, and John Munsell, professor in the College of Natural Resources and the Environment at Virginia Tech, each with extensive experience in agroforestry, summarize the lessons learned from a systematic analysis of these examples to develop a guide for groups involved with or intending to develop their own community food forest. This handbook effectively documents the state of the art of this emerging practice.

The introduction takes the reader, addressed as "you," on a discovery tour that reveals the enigmatic qualities of a community food forest-a seemingly wild arrangement of diverse plant communities with an open invitation to harvest or forage. The authors then parse the various elements that distinguish a community food forest from that of a natural forest or community garden. As a small-scale representation, food forests mimic the spatial patterns and functions of a forest ecology with three or more vertical layers of edible plants. They are also open and accessible to a broad public with intentional community participation.

This community aspect is also the critical dimension and primary emphasis of the book. While there are guides for establishing the biological components of food forests, such as the two-volume set, Edible Forest Gardens, by Dave Jacke and Eric Toensmeier, this handbook expands the discourse beyond recommendations for soil preparation or plant selection to address all the social considerations of how a food forest can be integrated into a community. It provides both the conceptual framework on social systems as well as practical tools for how to work with diverse stakeholders, engage communities, raise funds, assess leadership, and a range of other effective practices.

The book is organized into four sections. The first part, "Understanding Community Food Forests," provides background on the movement, and conceptual frameworks of systems thinking and the diverse set of capitals (social, human, natural, etc.) necessary to create and sustain a project. By presenting this framework, the handbook's structure allows readers to then choose relevant sections rather than follow a linear sequence. Readers inter- ested in getting grounded in agroecology, for instance, may want to skip to that chapter in Part 3, which also includes a discussion of the importance of public space and a comprehensive overview of the various allies such as landscape architects and urban foresters who can contribute to the multiple values of a community food forest. Part 2, which begins with a chapter on planning fundamentals, is perhaps the most useful section for anyone starting a community food forest, as it lays out the phases of project planning and management, including potential pitfalls to avoid. The final section, "Reflecting on Community," emphasizes the critical assessment of the community relationships, who the project is for, types of engagement, and especially, the power dynamics involved in a community-based project.

The challenge for any handbook is how to provide a comprehensive scope and practical guide with enough depth, rigor, and critical thought to make a meaningful contribution to readers with specific knowledge and expertise in related areas. This book effectively navigates the spectrum between these two objectives. Since community food forests are by definition hybrid spaces, the handbook brings together diverse knowledge sets, albeit at an introductory level. The tone is clearly aimed at the general reader and for that reason it would be difficult to use it as a main reference for academic purposes. However, its very effective grounding in systems thinking and theories of change and its models of different types of capital investments make this more than just a practical how-to guide. Its core strength throughout is the well-researched examples. These examples are embedded in each chapter to illustrate the concepts, and each section ends with a full chapter devoted to a specific case study.

The concluding chapter summarizes the extensive examples, concepts, and detailed guides into 10 themes presented as recommended actions, such as "Flexibility is Key," "Keep Adding Layers," or "Create a Governance Structure Early." Recognizing the early stage of development of the community food forest as a new typology and practice, the authors also identify critical needs for more urban food forestry research and developing networks for sharing information, expertise, and 
support across different projects. The primary contribution of the book is the sustained attention to the community aspect of food forests. Just as ecological design for food forests is based on ecosystem concepts of redundancy and multifunctionality, this handbook provides extensive guidance for how to initiate and sustain the social systems.

\section{References}

Jacke, D., \& Toensmeier, D. (2005). Edible forest gardens, Vol. 1, Ecological vision and theory for temperate climate permaculture. White River Junction, Vermont: Chelsea Green.

Jacke, D., \& Toensmeier, D. (2005). Edible forest gardens, Vol. 2, Ecological design and practice for temperate climate permaculture. White River Junction, Vermont: Chelsea Green. 